\title{
Risk assessment in the era of high-speed myocardial perfusion imaging
}

\author{
Fadi G. Hage, MD, FACC, ${ }^{\text {a,b }}$ Ankur Gupta, MBBS, ${ }^{a}$ \\ and Ami E. Iskandrian, MD, MACC, FASNC ${ }^{a}$
}

\section{See related article, pp. 1113-1123}

Over the last three decades, myocardial perfusion imaging (MPI) has had a proven track record for providing valid and useful prognostic information., Although its name implies that the test evaluates myocardial perfusion, several other prognostic variables have been derived from MPI over the years as shown in Figure 1 . Just as with any other diagnostic and/or prognostic test, the relative strength of each of these variables for the prediction of risk depends on patient selection, definition of normal/abnormal, definition of endpoint, and duration of follow-up. Even simple characterization of the MPI images as "normal" or "abnormal" separates patients into low- and high-risk groups with several folds difference in risk for hard cardiac endpoints. ${ }^{3}$ The patients with normal MPI have exceedingly low risk of cardiac events (although patients with normal vasodilator stress MPI have a higher event rate than those with normal exercise MPI), ${ }^{4}$ while patients with abnormal MPI have a higher event rate that increases commensurate with the degree of abnormality.

The study by Nakazato et $\mathrm{al}^{5}$ in this issue of the Journal employs a high-speed dedicated cardiac camera that uses a tungsten collimator and a solid-state cadmium zinc telluride (CZT) crystal in a highly efficient geometric design. The particular design used in their study has nine rotating detector columns each containing 1024 CZT crystals all focused on myocardium obtaining region of interest centric images. The $\mathrm{CZT}$ detectors are non-scintillating and convert gamma rays directly into digital signals, eliminating the need for photomultiplier

From the Division of Cardiovascular Diseases, ${ }^{\text {a }}$ University of Alabama at Birmingham, Birmingham, AL; Section of Cardiology, ${ }^{\mathrm{b}}$ Birmingham Veteran's Administration Medical Center, Birmingham, AL.

Reprint requests: Fadi G. Hage, MD, FACC, Division of Cardiovascular Diseases, University of Alabama at Birmingham, Zeigler Research Building 1024, 703 19th Street South, Birmingham, AL 35294-0006, USA; fadihage@uab.edu.

J Nucl Cardiol 2012;19:1102-5.

1071-3581/\$34.00

Copyright (C) 2012 American Society of Nuclear Cardiology.

doi:10.1007/s12350-012-9625-7 tubes. Each CZT crystal is fitted with a size matched square hole tungsten collimator. These collimators are shorter and wider than conventional lead collimators. This wide-angle collimation provides approximately 8 times higher acceptance of incident photons. ${ }^{6}$ This marked increase in count sensitivity over conventional Anger camera systems provides for lower use of radiation dose and markedly faster acquisition times. CZT crystals have almost twice the energy resolution of sodium iodide crystals which is advantageous for multi-isotope simultaneous imaging. With shorter imaging time, there is less opportunity for motion artifacts. Typically there is a trade-off between sensitivity and spatial resolution. ${ }^{7}$ In conventional systems, attempts to decrease radiation dose are met with lower image quality. With novel high-speedSPECT systems, the increased count sensitivity combined with higher energy resolution and software improvements actually increases the spatial resolution while reducing radiation dose and imaging times. Another major advantage of shorter imaging time is the improved patient comfort and efficient throughput of the laboratory.

The important contribution of Nakazato et $\mathrm{al}^{5}$ is that they demonstrated that quantitative analysis of perfusion abnormality by high-speed SPECT-MPI provides comparable prognostic results to conventional imaging. They thus followed 1,613 consecutive patients who underwent high-speed MPI for $2.6 \pm 0.5$ years during which $5 \%$ died. Stress perfusion defects were then assessed by automated analysis to calculate the total perfusion deficit (TPD) which reflects both extent and severity of the defect. With increasing TPD from $0 \%$ to $1 \%-2 \%, 2 \%-4 \%$, $5 \%-10 \%$, and $>10 \%$, annualized all-cause mortality increased from $0.87 \%$ to $1.55 \%, 2.22 \%, 3.10 \%$, and $5.33 \%$, respectively. In a multi-variable Cox regression analysis that adjusted for age, gender, hypertension, diabetes, known coronary disease, angina symptoms, and type of stress, TPD $>10 \%$ was associated with a 3 -fold increased risk of mortality compared to normal perfusion. Another remarkable observation from their study is the 9fold higher risk of death in the patients undergoing adenosine versus exercise MPI regardless of the perfusion pattern. The advantages of automated analysis over visual analysis was recently discussed. ${ }^{8}$ 


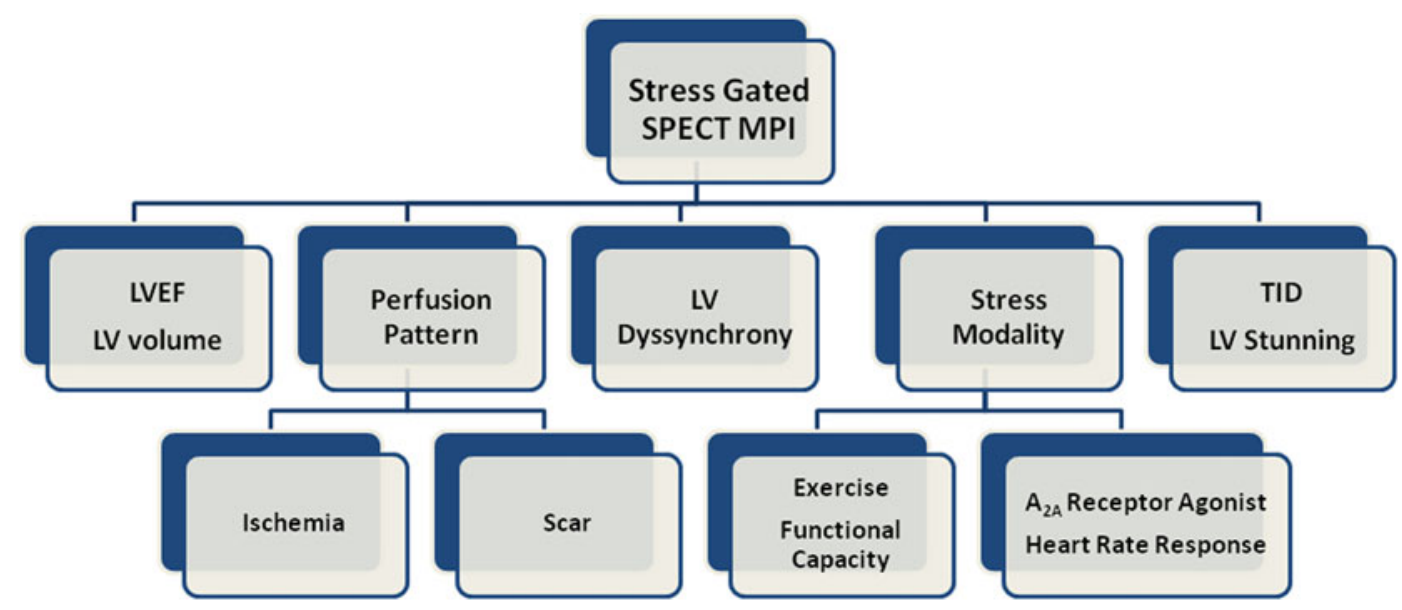

Figure 1. Variables of prognostic importance derived during stress myocardial perfusion imaging.

As can be expected from its success story, MPI had to evolve over the decades of its use, both in technology and in clinical application, to remain relevant to the practicing physician. The recent emphasis on encouraging physicians to identify and avoid the performance of inappropriate imaging (especially in asymptomatic individuals who are not at high risk, as a pre-operative assessment prior to low- or intermediate-risk noncardiac surgery, and routine serial testing after coronary revascularization), advertised by the Choose Wisely campaign which has been endorsed by the American Society of Nuclear Cardiology, ${ }^{9}$ has shed light on this important issue. Although it is true that utilization of imaging over the last few years has slightly (and likely appropriately) declined due to various pressures, the rate of increased use of MPI over longer periods of time is striking. ${ }^{10,11}$ Many factors have contributed to temporal changes in the rate of utilization of MPI including the impressive evidence base that accrued over time, the recently introduced appropriateness criteria and many others that are beyond the scope of this editorial. ${ }^{2,12}$ These same trends have also influenced the rate of abnormal test results (we are generally seeing less abnormalities in the current era). In parallel to the change in the rate of utilization of MPI, we have also witnessed a shift in ordering patterns favoring use of pharmacological stress as a replacement to exercise as a stress modality accompanying MPI. This shift is likely not only a reflection of decreasing functional capacity of the population but also the simplicity of using pharmacologic agents (especially regadenoson) in comparison to exercise protocols. Unfortunately, the important prognostic information gained from exercise testing ${ }^{13}$ is lost with pharmacologic stress. The heart rate response to adenosine or regadenoson has been shown to improve risk stratification models in symptomatic and asymptomatic individuals with normal and abnormal MPI ${ }^{14-16}$ and the information provided by this variable could help identify a low-risk subset among the population referred for pharmacologic MPI. Additional variables obtained from gated SPECT-MPI that promise to provide significant prognostic data include the off-line phase analysis of previously acquired perfusion images to determine the presence and severity of left ventricular (LV) dyssynchrony. ${ }^{17-19}$ Recently, quantitative measures of coronary flow reserve have been shown to provide important prognostic information. ${ }^{20}$ Although, so far, this has only been possibly with positron emission tomography, we anticipate that myocardial perfusion reserve ratio is, at least theoretically, possible using dynamic SPECT with high-speed cardiac camera and could be on the horizon.

Besides the prognostic information gained from baseline MPI, the change in perfusion pattern over time in a specific patient is also of value. This concept has been introduced by multiple studies including singlecenter studies, registries, and randomized trials, and is still evolving as using serial information in risk assessment is more complex than interpreting a single set of images. ${ }^{21}$ Recent results from Clinical Outcomes Utilizing Revascularization and Aggressive Drug Evaluation (COURAGE) and Bypass Angioplasty Revascularization Investigation 2 Diabetes (BARI 2D) show that both aggressive medical therapy and coronary revascularization improve perfusion pattern. ${ }^{22,23}$ Some patients with abnormal perfusion on initial imaging experience a change in perfusion pattern on repeat testing (spontaneously, after medical therapy or after coronary revascularization). Should the change from initial to subsequent study be used or should the results from the repeat study suffice? To complicate matters further, a change in LV ejection fraction (EF) could also occur and may or may not be in the same direction as the change in perfusion pattern. 
Does improvement or worsening track outcome as has been shown in a recent observational study ${ }^{24}$ and in COURAGE,${ }^{22}$ and how much improvement/worsening is the threshold? Should it be a relative or absolute change? For example a decrease from $10 \%$ to $5 \%$ is $5 \%$ absolute reduction but $50 \%$ relative reduction while a change from $50 \%$ to $45 \%$ is also a $5 \%$ absolute reduction but only a $10 \%$ relative reduction. While it is more intuitive to use the absolute change as an indicator of improvement/ worsening, it is hard to argue that a change in the size of a perfusion abnormality from $50 \%$ to $45 \%$ signifies clinically meaningful improvement. In trials, the improvement in outcome in patients with acute coronary syndromes is usually expressed as relative, rather than absolute, change. Another complexity involves the relationship of the change in perfusion with the perfusion pattern on the most recent study. For example, is a reduction from $20 \%$ to $15 \%$ in one patient associated with better outcome than worsening from $0 \%$ to $5 \%$ in another patient even though the final study shows a much larger abnormality in the first than the second patient?

An important consideration in interpreting quantitative data is that the various softwares for automated analyses differ from each other (and likely from visual analysis) and hence a threshold based on one software could not be assumed to work well in all laboratories. The use of a core laboratory in large clinical trials tends to overcome this limitation, at least for research purposes, but does not solve the issue when the cut-offs derived from these trials are used to guide clinical decision-making for studies performed in different laboratories with different softwares.

MPI is also used as a gateway to coronary angiography and revascularization in patients with stable disease. The cumulative evidence indicates that patients with normal perfusion (or with a small abnormality) on stress MPI do well with medical therapy. ${ }^{7}$ Coronary angiography, and revascularization, is usually reserved for such patients if severe symptoms are present and/or there is suspicion of a false negative test. The Fractional Flow Reserve Versus Angiography for Multi-vessel Evaluation (FAME) study showed that coronary revascularization guided by fractional flow reserve is superior to that guided by coronary angiography alone, ${ }^{25}$ and the FAME 2 study recently demonstrated the superiority of fractional flow reserve-guided percutaneous revascularization to optimal medical therapy (the primary composite outcome of death, myocardial infarction, or urgent revascularization was driven by a lower rate of urgent revascularization in the percutaneous coronary intervention group). ${ }^{26}$ Recent observational data suggest that targeted revascularization based on MPI in patients with multi-vessel disease also decreases the rate of major adverse cardiac events compared to that based on coronary angiography. ${ }^{27}$ However, to date there has been no direct evidence that an invasive strategy involving coronary revascularization is superior to optimal medical therapy in patients with stable coronary artery disease regardless of the presence of absence of ischemia.

The NIH-NHLBI sponsored the international study of comparative health effectiveness with medical and invasive approaches (ISCHEMIA) trial will be conducted in $\sim 8,000$ patients from $\sim 400$ worldwide centers. ${ }^{28}$ The ISCHEMIA trial will compare a strategy of catheterization-guided care with optimal coronary revascularization to conservative strategy with catheterization reserved for patients with refractory angina, acute coronary syndrome, acute ischemic heart failure, or resuscitated cardiac arrest. Importantly, only patients with moderate-severe ischemia will be enrolled, defined with stress MPI as $\geq 10 \%$ ischemic myocardium. All patients will undergo a blinded coronary computed tomographic angiography to exclude significant left main stenosis and to rule out nonobstructive coronary disease and all patients will receive optimal medical therapy.

The decision for and against coronary angiography and revascularization is surely complex and evolving. The ultimate challenge is how to personalize the MPI risk assessment data and convey that information to the referring physician. We envision an algorithm that incorporates clinical and MPI data (Figure 2) based on statistical modeling that would need to be generated and then verified in more than one group of patients. The registry concept that ASNC is embarking on may make this a possibility. We have now journeyed a full circle from catheterization- to physiological-based decisionmaking with respect to coronary revascularization, all within our-life time; remarkable indeed.
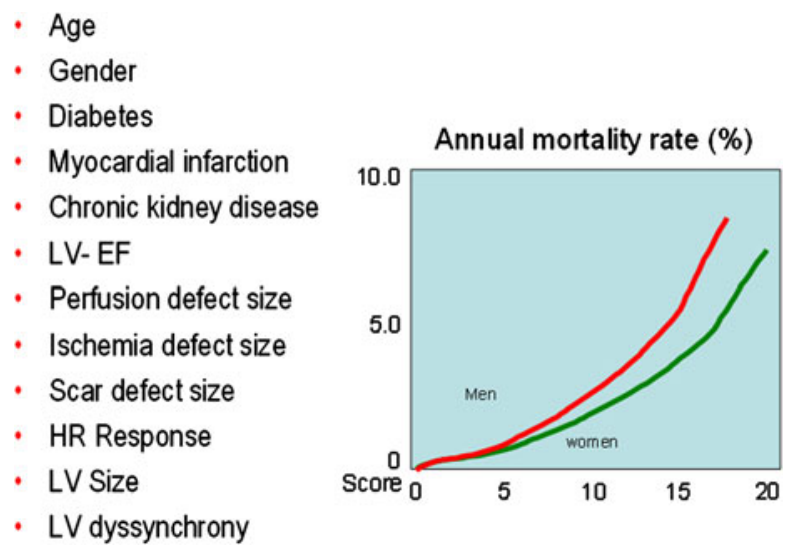

Figure 2. A scheme for personalized medicine. A simulated model using a hypothetical score that incorporates clinical and MPI variables to predict future annual mortality rate in men and women is shown. 


\section{References}

1. Iskandrian AE, Garcia EV. Atlas of nuclear cardiology: Imaging companion to Braunwald's heart disease. Philadelphia, PA: Elsevier; 2012. p. 472

2. Shaw LJ, Hage FG, Berman DS, Hachamovitch R, Iskandrian A. Prognosis in the era of comparative effectiveness research: Where is nuclear cardiology now and where should it be? J Nucl Cardiol 2012. doi:10.1007/s12350-012-9593-y.

3. Iskander $\mathrm{S}$, Iskandrian AE. Risk assessment using single-photon emission computed tomographic technetium-99m sestamibi imaging. J Am Coll Cardiol 1998;32:57-62.

4. Rozanski A, Gransar H, Hayes SW, Friedman JD, Hachamovitch R, Berman DS. Comparison of long-term mortality risk following normal exercise vs adenosine myocardial perfusion SPECT. J Nucl Cardiol 2010;17:999-1008.

5. Nakazato R, Berman DS, Gransar H, Hyun M, Miranda-Peats R, Kite FC, et al. Prognostic value of quantitative high-speed myocardial perfusion imaging. J Nucl Cardiol 2012. doi:10.1007/s12350012-9619-5.

6. Gambhir SS, Berman DS, Ziffer J, Nagler M, Sandler M, Patton J, et al. A novel high-sensitivity rapid-acquisition single-photon cardiac imaging camera. J Nucl Med 2009;50:635-43.

7. Iskandrian AE, Garcia EV. Nuclear cardiac imaging: Principles and applications. Oxford: Oxford University Press; 2008.

8. Iskandrian AE, Garcia EV, Faber T, Mahmarian JJ. Automated assessment of serial SPECT myocardial perfusion images. J Nucl Cardiol 2009;16:6-9.

9. http://www.asnc.org/media/ASNC1509\%20ChooseWisely\%20JNC r2.pdf. Assessed August 28, 2012.

10. Shaw LJ, Min JK, Hachamovitch R, Peterson ED, Hendel RC, Woodard PK, et al. Cardiovascular imaging research at the crossroads. J Am Coll Cardiol Imaging 2010;3:316-24.

11. Levin DC, Rao VM, Parker L, Frangos AJ, Intenzo CM. Recent payment and utilization trends in radionuclide myocardial perfusion imaging: Comparison between self-referral and referral to radiologists. J Am Coll Radiol 2009;6:437-41.

12. Shaw LJ, Iskandrian AE. Prognostic value of gated myocardial perfusion SPECT. J Nucl Cardiol 2004;11:171-85.

13. Bourque JM, Charlton GT, Holland BH, Belyea CM, Watson DD, Beller GA. Prognosis in patients achieving $\geq 10$ METS on exercise stress testing: Was SPECT imaging useful? J Nucl Cardiol 2011; 18:230-7.

14. Hage FG, Dean P, Bhatia V, Iqbal F, Heo J, Iskandrian AE. The prognostic value of the heart rate response to adenosine in relation to diabetes mellitus and chronic kidney disease. Am Heart J 2011; 162:356-62.

15. Hage FG, Dean P, Iqbal F, Heo J, Iskandrian AE. A blunted heart rate response to regadenoson is an independent prognostic indicator in patients undergoing myocardial perfusion imaging. J Nucl Cardiol 2011;18:1086-94.

16. Hage FG, Wackers FJ, Bansal S, Chyun DA, Young LH, Inzucchi SE, et al. The heart rate response to adenosine: A simple predictor of adverse cardiac outcomes in asymptomatic patients with type 2 diabetes. Int J Cardiol 2012. doi:10.1016/j.ijcard.2012.08.011.

17. Chen J, Garcia EV, Bax JJ, Iskandrian AE, Borges-Neto S, Soman P. SPECT myocardial perfusion imaging for the assessment of left ventricular mechanical dyssynchrony. J Nucl Cardiol 2011;18:685-94.

18. AlJaroudi W, Aggarwal H, Venkataraman R, Heo J, Iskandrian AE, Hage FG. Impact of left ventricular dyssynchrony by phase analysis on cardiovascular outcomes in patients with end-stage renal disease. J Nucl Cardiol 2010;17:1058-64.

19. Aljaroudi WA, Hage FG, Hermann D, Doppalapudi H, Venkataraman R, Heo J, et al. Relation of left-ventricular dyssynchrony by phase analysis of gated SPECT images and cardiovascular events in patients with implantable cardiac defibrillators. J Nucl Cardiol 2010;17:398-404.

20. Murthy VL, Naya M, Foster CR, Hainer J, Gaber M, Di Carli G, et al. Improved cardiac risk assessment with noninvasive measures of coronary flow reserve. Circulation 2011;124:2215-24.

21. Iskandrian AE, Garcia EV, Faber T. Analysis of serial images: A challenge and an opportunity. J Nucl Cardiol 2008;15:23-6.

22. Shaw LJ, Berman DS, Maron DJ, Mancini GB, Hayes SW, Hartigan PM, et al. Optimal medical therapy with or without percutaneous coronary intervention to reduce ischemic burden: results from the Clinical Outcomes Utilizing Revascularization and Aggressive Drug Evaluation (COURAGE) trial nuclear substudy. Circulation 2008;117:1283-91.

23. Shaw LJ, Cerqueira MD, Brooks MM, Althouse AD, Sansing VV, Beller GA, et al. Impact of left ventricular function and the extent of ischemia and scar by stress myocardial perfusion imaging on prognosis and therapeutic risk reduction in diabetic patients with coronary artery disease: Results from the Bypass Angioplasty Revascularization Investigation 2 Diabetes (BARI 2D) trial. J Nucl Cardiol 2012;19:658-69.

24. Farzaneh-Far A, Phillips HR, Shaw LK, Starr AZ, Fiuzat M, O'Connor CM, et al. Ischemia change in stable coronary artery disease is an independent predictor of death and myocardial infarction. J Am Coll Cardiol Imaging 2012;5:715-24.

25. Pijls NH, Fearon WF, Tonino PA, Siebert U, Ikeno F, Bornschein $\mathrm{B}$, et al. Fractional flow reserve versus angiography for guiding percutaneous coronary intervention in patients with multivessel coronary artery disease: 2-year follow-up of the FAME (Fractional Flow Reserve Versus Angiography for Multivessel Evaluation) study. J Am Coll Cardiol 2010;56:177-84.

26. De Bruyne B, Pijls NH, Kalesan B, Barbato E, Tonino PA, Piroth $\mathrm{Z}$, et al. Fractional flow reserve-guided PCI versus medical therapy in stable coronary disease. N Engl J Med 2012. doi:10.1056/NEJ Moa1205361.

27. Kim YH, Ahn JM, Park DW, Song HG, Lee JY, Kim WJ, et al. Impact of ischemia-guided revascularization with myocardial perfusion imaging for patients with multivessel coronary disease. $\mathbf{J}$ Am Coll Cardiol 2012;60:181-90.

28. https://ischemiatrial.org/for-physicians/Executive_Summary_ISC HEMIA_November_2011_Final.pdf. Accessed August 25, 2012. 